\title{
Concurrencia de meningioma y astrocitoma: breve reporte de caso
}

Luis Rafael Moscote-Salazar1, Andrés M. Rubiano², Hernando Raphael Alvis-Miranda ${ }^{3}$

1 Neurocirujano. Universidad de Cartagena, Colombia.

2 Neurocirujano. Hospital Universitario de Neiva.

3 Residente de Neurocirugía. Universidad de Cartagena, Colombia.

Rev. Chil. Neurocirugía 42: 62-63, 2016

\section{Resumen}

Las neoplasias intracraneales múltiples son infrecuentes, representan alrededor del $4 \%$ de todos los tumores cerebrales. Estas lesiones se observan ocasionalmente en pacientes con neurofibromatosis y en tratados con radioterapia. Presentamos el caso de un paciente portador de meningioma y una lesión de estirpe glial manejado en nuestro servicio de neurocirugía.

Palabras clave: Astrocitoma, meningioma, tumores cerebrales.

\begin{abstract}
Multiple intracranial neoplasms are rare, representing about $4 \%$ of all brain tumors. These lesions are occasionaly observed in patients with neurofibromatosis and in patients treated with radiotherapy. We report the case of a patient with a meningioma and a glial lineage lesion, handled in our service of neurosurgery, University of Cartagena, Colombia.
\end{abstract}

Key words: Astrocytoma, meningioma, brain tumors.

\section{Introducción}

Los tumores del sistema nervioso central representan un grupo de entidades diversas en morfología, ubicación, biología molecular y comportamiento clíni$\mathrm{co}^{3}$. En Europa, la incidencia estandarizada (mundial) de tumores primarios del SNC varía entre 4,5 a 11,2 casos por cada 100.000 hombres y de 1,6 a 8,5 casos por cada 100.000 mujeres $^{4}$. En Sur América, se ha reportado ser de 2,4 por cada 100.000 hombres y de 1,9 por cada 100.000 mujeres. La incidencia de tumores intracraneales ha incrementado con respecto al comportamiento epidemiológico reportado antes de 1980, en parte debido al advenimiento de nuevas tecnologías imagenológicas como la tomografía computarizada (TAC) y la resonancia magnética.
Se ha reportado que la mayoría de los tumores están representados por los gliomas, con una tasa de incidencia ajustada para la edad entre $-0,5 \%$ a $-0,8 \%(p \leq 0,034)$, también se ha observado un incremento particular de estos en el lóbulo frontal con una tasa de incidencia ajustada para la edad de $+1,4 \% a+1,7 \%(P \leq 0,012$. Los tumores de origen astrocítico, oligodendroglial y ependimal representan entre el 70 y el $75 \%$ de estos tumores. Como hallazgo fortuito en la evaluación de RM por otra causa, los tumores cerebrales benignos representan un 1,6\%, siendo los meningiomas los más frecuentemente encontrado. Las neoplasias intracraneales múltiples son infrecuentes, representan alrededor del $4 \%$ de todos los tumores cerebrales. A continuación presentamos un caso de esta inusual asociación tumoral.

\section{Reporte de Caso}

Paciente masculino de 48 años sin antecedentes de importancia, que consulta por cuadro clínico de cefalea de 6 meses de evolución precedida desde hace varios meses por crisis parciales motoras en hemicuerpo izquierda y torpeza psicomotriz. En la exploración se objetiva bradipsiquia sin otra focalidad neurológica. Se procede a realizar estudios de neuroimagen (Figura 1 A, B, C D), RM secuencia ponderadas en $\mathrm{T} 1$, con gadolineo, que evidencia la presencia de una lesión en el hemisferio derecho, intraaxial, la primera. La segunda de localización frontal, con edema perilesional. Se realiza una craneotomía derecha, extirpándose un tumor $2 \mathrm{~cm}$ de diámetro, que muestra un componente intraparenquimatoso sin plano de clivaje. El estudio histo- 


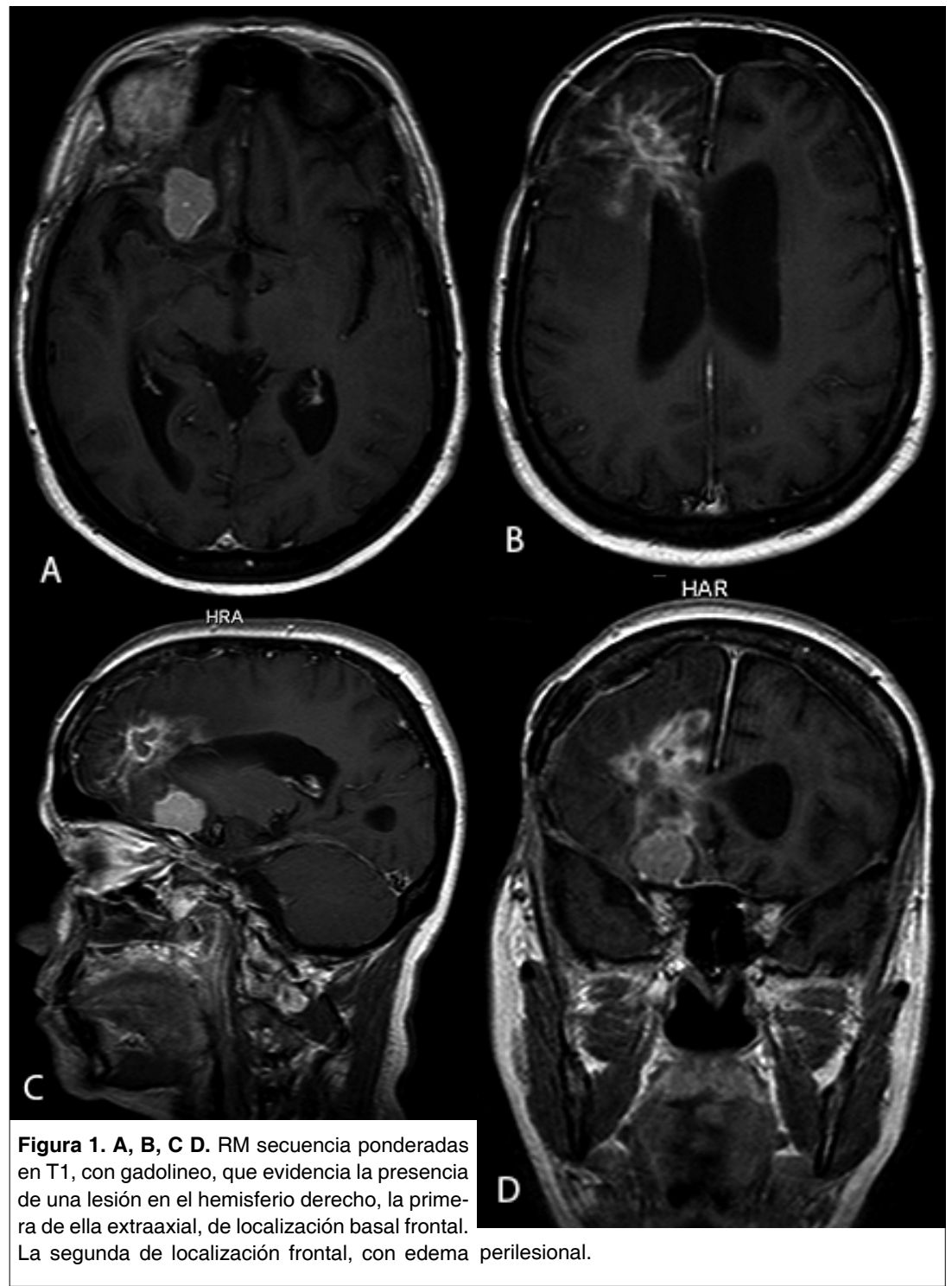

patológico correspondio a Astrocitoma anaplasico (Grado III OMS). Se reseco parcialmente una lesión frontal basal, la neoplasia meníngea con células meningoteliales. El paciente presento evolución satisfactoria y fue remitido a otra institución para manejo neurooncologico.

\section{Discusión}

En la literatura médica con frecuencia se reportan series en las que un mismo paciente presenta de manera sincrónica dos tipos de neoplasias en distintas localizaciones de la anatomía cerebral. No obstante, el hallazgo de dos o más tipos de neoplasias en una misma localización, denominado como "asociación tumoral intracraneal" o "tumores en colisión", es un fenómeno excepcional1 ${ }^{1,2,3}$. En ambos casos, las líneas celulares más prevalentes son las de estirpe meníngeo y glial (mayormente astrocitomas), más no las metástasis como sería de suponerse por ser las neoplasias cerebrales más frecuentemente encontradas en los casos de una sola línea. Otras asociaciones menos frecuentes son las de glioblastoma multiforme y sarcoma, meningioma y adenoma hipofisario o glioblastoma y adenoma hipofisario. Debe tenerse claro que este hecho puede presentarse en patologías con sustrato genético, tal como el síndrome de von Hippel Lindau y las neurofibromatosis, donde existen más de una localización de los tumores a nivel del sistema nervioso central; en su mayoría de una misma estirpe, y donde es frecuente encontrar además de meningiomas, ependimomas, schwanomas y neurofibromas, entre otros ${ }^{4,5,6}$.

Aún no hay una explicación clara y con sustento científico válido, que justifique este fenómeno. Se sabe que a partir de radioterapia, puede inducirse la génesis de más de una línea celular, en su mayoría de forma metacrónica. Sin embargo, en ausencia de este antecedente, existen sólo teorías. Algunas orientadas hacia la producción de factores oncogénicos comunes en las vías metabólicas de las líneas celulares implicadas. Afirmaciones que aún son materia de investigación.

Recibido: 29 de octubre de 2015 Aceptado: 02 de diciembre de 2015

\section{Bibliografía}

1. Prayson RA, Chowdhary S, Woodhouse S, Hanson M, Nair S. Collision of a Syncytial Meningioma and Malignant Astrocytoma. Ann Diagn Pathol 2002; 6: 44-48.

2. Hope AJ, Mansur DB, Tu PH, Simpson JR. Metachronous secondary atypical meningioma and anaplastic astrocytoma after postoperative craniospinal irradiation for medulloblastoma. Childs Nerv Syst 2006; 22: 1201-1207.

3. Kheirollahi M, Mehrazin M, Kamalian N, Mohammadi-asI J, Mehdipour P. Telomerase Activity in Human Brain Tumors: Astrocytoma and Meningioma. Cell Mol Neurobiol 2013; 33: 569-574.

4. Gutiérrez - González R, Boto GR, Pérez-Zamarrón A, Rivero - Garvía M. Asociación tumoral intracraneal: coexistencia de glioma de bajo grado, glioblastoma multiforme y meningioma en el mismo paciente. Neurocirugía 2009; 20: 176-180.

5. Spallone A, Santoro A, Palatinsky E, Giunta F. Intracranial meningiomas associated with glial tumors: a review based on 54 selected literature cases from the literature and 3 additional personal cases. Acta Neurochir (Wien) (1991) 110: 133-139.

6. Dario A, Marra A, Cerati M, Scamoni A, Dorizzi A. Intracranial meningioma and astrocytoma in the same patient. Case report and review of the literature. J Neurosurg Sci 1995 Mar; 39(1): 27-35.

Correspondencia a:

Dr. Luis Rafael Moscote. Universidad de Cartagena, Cartagena de Indias, Colombia. mineurocirujano@aol.com 